\title{
Carbon Tax, Emission Standards, and Carbon Leak Under Price Competition
}

\author{
Paolo Giorgio Garella ${ }^{1}$ - Maria Teresa Trentinaglia ${ }^{2}$
}

Accepted: 28 February 2018

(C) Springer Science+Business Media B.V., part of Springer Nature 2018

\begin{abstract}
We consider a two-country model of price competition, with one polluting firm in each country and differentiated products. Assuming away, to simplify, abatement efforts and input substitution, we compare the impact on output, leakages, and trade volumes of a carbon tax versus an emission standard policy, unilaterally enacted by the home country. Under the tax the two firms set their prices simultaneously, in a Bertrand game. Under the standard the home firm's price is conditioned on the price of the foreign firm, so as to abide the emission constraint. As a result, the tax leads to higher leakages and global emissions than the standard. The standard also implies a better trade balance for the home country than the tax.
\end{abstract}

Keywords Carbon leakage $\cdot$ Carbon tax $\cdot$ Emission standards $\cdot$ Trade balance $\cdot$ Price competition

\section{Introduction}

Efforts by industrialized countries to reduce polluting emissions have been accompanied by concerns over the effectiveness of unilateral measures, in terms of both welfare loss and carbon leakages. It is in fact well established in the literature that measures targeting a subset

Maria Teresa Trentinaglia

mttrentinaglia@gmail.com ; maria.trentinaglia@unibocconi.it

Paolo Giorgio Garella

paolo.garella@unimi.it

1 Department of Economics, Managament and Quantitative Methods, Università degli Studi di Milano, Via Conservatorio 7, 20122 Milan, Italy

2 Department of Environmental Science and Policy, Università degli Studi di Milano, Via Celoria 2, 20122 Milan, Italy 
of manufacturers within a country (Fowlie 2009; Holland 2012) ${ }^{1}$ or manufacturers in only a subset of countries (incomplete regulation) can induce production and emission leakages to unregulated firms and in other countries (Paltsev 2001), or they can encourage domestic firms to relocate plants (Babiker 2005). The high variability of "leakages" rates reported in the literature (see, for references, Barker et al. 2007; Baylis et al. 2014; Sanna-Randaccio et al. 2014) makes the debate still lively. Hence, considerable attention has been devoted to the analysis of these mechanisms - several contributions also analyzing countervailing measures, like border tax adjustments or upstream-downstream subsidies (Fischer and Fox 2012; Fischer et al. 2012).

A related question is which type of policy minimizes leakages. For instance, intensity standards, that set limits to carbon emissions per unit of output, have been proved to be inefficient (Fischer 2001; Holland et al. 2009), since "they cannot attain the first best, could increase carbon emissions", and entail "much higher abatement costs than an efficient policy" (see Holland et al. 2009, p. 1). Still, according to Holland (2012), intensity standards can be welfare superior to a carbon tax and allow for a second best outcome, in the presence of incomplete regulation and leakages.

So far, most of the existing literature on carbon leakages arising from local or incomplete regulation focuses on perfectly competitive markets. However, most issues in environmental regulation have been widely analyzed also in the context of oligopolistic industries [Arora and Gangopadhyay (1995), Amacher et al. (2004), and Moraga-González and Padrón-Fumero (2002) are concerned with environmental qualities in a duopoly; Toshimitsu (2008), Kurtyka and Mahenc (2011), and Carlsson (2000) deal with environmental taxation in duopolies; Lahiri and Ono (2007) compare welfare under permits and taxes; Requate (2006) provides a summary view]. Furthermore, as argued by Fowlie (2009), "The majority of emissions that are currently subject to regional, market-based regulations come from industries that are often characterized as imperfectly competitive (important examples include restructured electricity markets and cement)" (see Fowlie 2009, p. 73). Finally, Ryan (2012) and Fowlie et al. (2012) supply evidence that concentrated industries are crucially affected by environmental regulation; using data for the U.S. Portland cement industry, the first provides an assessment of welfare reductions and increase in sunk costs, and the second of the welfare losses and "leakages" from incomplete regulation.

Based on these considerations, in this paper we analyze the implementation of an environmental policy under imperfect competition in prices, and its consequences in terms of both carbon leakages and trade only, thus neglecting the welfare effects. In the baseline version of the model, we assume that firms cannot price discriminate across countries. This assumption may fit the case where leakages occur within the same country due to incomplete regulation, while also serving as a first approximation for a two country model. In the second version of the model, we allow firms to price discriminate across countries. On top of deriving carbon leakages, we also consider the effects on the international competitiveness of the regulated country, by assessing the impact on its trade balance.

\footnotetext{
1 "For political, jurisdictional and technical reasons, environmental regulation of industrial pollution is often incomplete: rules apply to only a subset of the sources contributing to a pollution problem. When some firms in a polluting industry are subject to market-based environmental regulation (such as a pollution tax or pollution permit trading program) while others are exempt, the production costs of regulated producers will increase relative to their unregulated rivals. If unregulated production can be easily substituted for production at regulated firms, emissions reductions achieved by regulated producers may be substantially offset, or even eliminated, by increases in emissions among unregulated producers." (See Fowlie 2009, p. 72).
} 
We compare the effects of two alternative instruments, a carbon tax and an emission standard; the latter is defined as the maximum quantity of emissions by the regulated firm. ${ }^{2}$ Both policies come as exogenous shocks to the firm in the regulated country. Nonetheless, to enable meaningful comparisons, the policy instruments that the regulator can introduce are tailored so as to guarantee the same level of emissions in the home country. Hence, the tax level set by the Regulator is such that an "equivalent tax" is achieved. We do not consider abatement efforts and focus instead on the effects generated by strategic interaction in price competition. Although we think that abatement would also be affected, the focus on pricing strategies allows to reveal a channel of "transmission" of policies that per se is sufficient to bring forth leakage effects. Since firms are assumed to be immobile, ${ }^{3}$ leakages arise due to a shift in production and trade patterns, and not from firms' relocation abroad (see instead Petrakis and Xepapadeas 2003; Sanna-Randaccio et al. 2014).

The key assumption we make is that under a tax policy firms set their prices simultaneously, while under a standard the two firms move in a Stackelberg-type sequence with the (regulated) home firm moving only after having observed the price set by the foreign competitor. The assumption and the modeling strategy are explained and justified as follows. An emission standard implies a cap on the home firm's output, since we analyze a short-run without abatement efforts, with firms being unable to reduce their emissions per unit of output ratio. This assumption is justifiable in a short run analysis where fixed factors cannot be changed and/or new technologies cannot be made available without discontinuous changes in costs, that make them unprofitable, or without investments in $R \& D$ that take time to deliver their results. Sunk abatement costs may also play a role in deterring abatement efforts as recognized by Pindyck (2007) (see also Saltari and Travaglini (2011) and the references therein). ${ }^{4}$ It follows that the regulated firm (firm 1) must exclude from its possible responses all the prices that do not satisfy the constraint; in this way the action set of firm 1 becomes a function of the price chosen by the rival — and of the emission cap. More simply, the set of admissible prices for firm 1 under a standard contains all prices larger or equal to a minimum price which depends upon the rival's price and upon the emission standard.

A first consequence of this dependence is that a simultaneous representation of the game is in contrast with the need to have firm 1 informed $^{5}$ about which values for its price are "legal" for a given price of the rival- since values for the home firm price are not per se illegal but only in relation to the rival's price. A second consequence of this dependence is

\footnotetext{
${ }^{2}$ Since regulation is exogenously implemented in one country only, there is no trade in permits. Hence, emission standards and tradable permits are equivalent policy instruments in our context. If there were two regulated firms in the home country trade in permits would enable these firms to reallocate emission quotas but the final outcome, that the total production in the home country remain fixed would not be altered. Assuming permits are granted in equal amounts to each firm, trade in permits would not occur in a model where home firms are identical; the algebra for this model is more complicated but our results are confirmed.

3 As in the short run or due to technological constraints.

${ }^{4}$ We do not claim that abatement possibilities are irrelevant. The inclusion of abatement efforts that make the unit emission level $\beta$ a function of abatement expenditures, $k$, say, may offset some of the results, but only if a tax induces larger abatement by firm 1 than a standard (firm 2 does not need to abate). Even in that case, the total impact on the production of the unregulated firm (leakages) would depend crucially upon the amount of abatement induced on firm 1 and hence finally on the parameters shaping the marginal abatement cost function. Low marginal abatement costs may reverse the results if a tax induces higher abatement than a standard; high abatement costs will not reverse the results.

5 In any representation of a game in extensive form the player that must move at a given information set must have the same set of available actions in any of the nodes contained in that information set (Mas-Colell et al. 1995; Kuhn 1953). If a player had different choices available at different nodes in an information set than he could infer from the available choices the node at which he is called to play, and the nodes cannot belong then to the same set.
} 
that the usual way to check whether a pair of prices is a Nash equilibrium is invalidated. To be precise, starting from any candidate equilibrium price pair, the unregulated firm (firm 2) will recognize that it may become impossible for firm 1 to stick to the candidate equilibrium price. A deviation by firm 2 will then forcibly lead to a change in the price set by firm 1 as well. The feature that the strategy space of a player depends upon the choice of strategy made by another player is anomalous in simultaneous games, while it is quite common in sequential games. These considerations explain why the modeling adopted here for the emission standard takes the form of a sequential game and leads to a solution with the Stackelberg character.

The effect of a carbon tax, by contrast, is simply to increase the marginal cost of the home firm, shifting upwards its reaction function (Anderson et al. 2001). We insist that a tax does not preclude any pair of prices as a possible solution; any positive price is always admissible for firm 1 and therefore there is no need to have firm 1 being informed about the rival's choice.

The comparison of prices under the two policies reveals that under a an emission standard, both firms set higher prices than under an equivalent tax. This is essentially due to the role played by firm 2 in setting its own price, exploiting the constraint imposed on firm 1. Indeed, if firms are assumed to move simultaneously, as discussed later in Sect. 2.4, the two policies lead to the same price vector and quantities. This is because the tax level is computed so as to lead to the same equilibrium quantity for firm 1-determined by the policy-maker choiceas under the standard; then, this quantity equivalence in a simultaneous game can only be granted by a shift of the best reply of firm 1 (under a tax this is just an ordinary linear best reply) till the crossing of the two best replies occurs at the same equilibrium price vector. Therefore, the forced price adjustment to the constraint by the home firm and the induced change in the behavior of the foreign firm, absent in the simultaneous game, are the key elements driving the results.

We confirm the existing concerns over unilateral environmental regulation in the case of a carbon tax (see Paltsev 2001; Holland 2012), which indeed induces an unwanted increase in emissions by unregulated countries. We observe that an emission standard policy can even reduce emissions abroad, although this negative carbon leakage can occur only for very large targeted emission reductions. At any rate, the general message is that an emission standard leads to less leakage than a carbon tax.

We then assess the inferiority of the carbon tax also with respect to the trade balance: because of the larger leakage, a carbon tax has negative effects on the home country trade balance, whereas the emission standard may ultimately improve it (or induce lower negative effects than a carbon tax). Overall, our findings point to the superiority of an emission standard over a carbon tax.

Our findings depart from Holland (2012), where the inferiority of a standard stems from the firms changing their input compositions, choosing different emission levels in their cost minimization problem. ${ }^{6}$ In an extension of the baseline model, we briefly analyze the outcome of a game where firms choose their prices simultaneously under a standard. In this setting, the solution is given by the intersection point of the unregulated firm best reply function and the constrained price of the home firm. We observe that the emissions, and hence the carbon leakage, of firm 2 are the same as under a carbon tax. Hence our results suggest that, if a simultaneous game were deemed plausible, the regulator may be indifferent between the two alternative policy instruments.

6 In our framework instead, input composition is fixed and the relative superiority of emission standards is intrinsic to the strategic interaction occurring between the firms in the two countries. 
This work is structured as follows: Sect. 2 sets up the general model and analyzes the simplified case of a globally integrated demand with no price discrimination; Sect. 3 develops the full discrimination case as well as the trade balance analysis; last, Sect. 4 draws the main conclusions. "Appendix I" summarizes and compares the equilibria obtained and discussed throughout Sect. 2; "Appendix II" contains some algebra for the price discrimination model; in "Appendix III", we consider the effect of environmental regulation on the trade values of the regulated country.

\section{The Model}

\subsection{The General Model}

We assume that there is only one firm in the home country $\mathrm{H}$ and one firm in the foreign country $\mathrm{F}$, both in a polluting industrial sector. Alternatively, we may also think of these two firms as being located in the same country but being subject to two different environmental regulations: one firm may in fact belong to a regulated sector, and the other to an unregulated industry producing a substitute product. In our baseline setting, we rule out price discrimination, whereas in the international two country model analyzed in Sect. 3, firms do price discriminate across countries.

The government in country $\mathrm{H}$ decides to reduce domestically produced emissions to a given level, $s$, below the current level achieved under an unrestricted market equilibrium. The government in country $\mathrm{H}$ can use one of two policies: either introduce a carbon tax $t_{e}$, on each unit of pollutant, or target an overall emission level, assumed to be exogenous. Similarly, the firm in country F, or in the "other sector", could be subject to an exogenous "carbon" tax (see Baylis et al. 2014), without substantially affecting our results. ${ }^{7}$

The quantity of emissions per unit of production by the domestic firm is $\beta$, with $0<\beta \leq 1$, while that of the foreign firm is set equal to 1 , in order to simplify exposition and without loss of generality. The domestic firm is denoted as firm 1 and the foreign firm as firm 2 . Production costs are $C_{i}\left(q_{i}\right)=c_{i} q_{i}$ for $i=1,2$.

The firms' products are differentiated and firms behave as Bertrand competitors. Product differentiation is reflected by $\gamma \in(0,1)$, with $\gamma=0$ for independent goods (no perfect substitution is allowed, namely $\gamma=1$ is ruled out). We have normalized to 1 the parameter for the own price in the demand function of good $i$, therefore we impose the realistic restriction $\gamma<1$, namely that the own price effect on demand is greater in size than the cross effect of a change in the price of the rival good. ${ }^{8}$ The direct demand functions in country $\mathrm{H}$ and $\mathrm{F}$ for

\footnotetext{
${ }^{7}$ In Holland (2012), firms can instead choose the level of emissions $e$, a costless input, together with another costly input, so as to minimize their cost function.

8 Our approach is akin to Hackner (2000), where a utility function of the type as in Singh and Vives (1984), $U\left(q_{1}, q_{2}\right)=\alpha_{1} q_{1}+\alpha_{2} q_{2}-(1 / 2)\left(\beta_{1} q_{1}^{2}+\beta_{2} q_{2}^{2}+2 \gamma q_{1} q_{2}\right)$ is rewritten with the restriction $\beta_{i}=1$. In $U\left(q_{1}, q_{2}\right)$, if $\gamma=\beta_{1}=\beta_{2}$ (in Hackner (2000), if $\gamma=1$ ), the two goods are perfect substitutes - as utility only depends upon the sum $q_{1}+q_{2}$. First order conditions then give indirect demand functions $p_{i}=\alpha_{i}-q_{i}-\gamma q_{j}$, for $i, j=1,2$. The corresponding direct demand system preserves symmetry in the cross effect (cross price elasticities are identical) and is of the form: $q_{i}=a_{i}-b_{i} p_{i}+c p_{j}$, where in particular $c=\gamma /\left(1-\gamma^{2}\right)$. In order to simplify the algebra, we have rewritten the direct demand as $q_{i}=A_{i}-p_{i}+\gamma p_{j}$. This is not a substantial change however, and to see that our approach is as in Hackner (2000) consider $U\left(q_{1}, q_{2}\right)$ with $\beta_{1}=\beta_{2}=1$, and transform it as $V\left(q_{1}, q_{2}\right)=\left(1-\gamma^{2}\right)^{-1} U\left(q_{1}, q_{2}\right)$. Then $V\left(q_{1}, q_{2}\right)$ and $U\left(q_{1}, q_{2}\right)$ represent the same preference ordering. Maximization of $V\left(q_{1}, q_{2}\right)$ leads to the first order condition $\left(1-\gamma^{2}\right) p_{i}=\alpha_{i}-q_{i}-\gamma q_{j}$, hence the demand system of our model obtains as $q_{i}=A_{i}-p_{i}+\gamma p_{j}$, with $A_{i}=\alpha /(1+\gamma)$. As in the standard approach, the two goods tend to be perfect substitutes if $\gamma$ tends to 1 .
} 
$i=1,2$ with $i \neq j$ are, respectively:

$$
\begin{aligned}
q_{i}^{h}\left(p_{i}^{h}, p_{j}^{h}\right) & =A+\gamma p_{j}^{h}-p_{i}^{h} \\
q_{i}^{f}\left(p_{i}^{f}, p_{j}^{f}\right) & =B+\gamma p_{j}^{f}-p_{i}^{f}
\end{aligned}
$$

where $p_{i}^{h}, p_{i}^{f}$ represent the prices quoted by firm $i$ in country $\mathrm{H}$ and $\mathrm{F}$ respectively.

A carbon tax is a unit tax on emissions. The only firm paying the tax under a tax policy is the home firm. The carbon tax implies an increase in the marginal cost of production for the home firm from $c_{1}$ to $c_{1}+\beta t$, given the exogenous emission rate $\beta$.

The emission standard, by contrast, sets an implicit limit on production by the home firm: ${ }^{9}$ if the level of allowed emissions is $s$, that is $q \beta=s$, total production by the home firm cannot exceed the quantity $s / \beta$. Emissions above this floor imply a penalty, $w$. Hence, to avoid the emission penalty, firm 1 must choose the price pair $\left(p_{1}^{h}, p_{1}^{f}\right)$ that satisfies the following constraint:

$$
A+B+\gamma\left(p_{2}^{h}+p_{2}^{f}\right)-p_{1}^{h}-p_{1}^{f} \leq s / \beta .
$$

For the remaining of the analysis we shall assume that the foreign country is not adopting any policy concerning emissions - or that firm 2 is not subject to regulation. Carbon leak is usually defined as the ratio between the changes in emissions, as in Fischer and Fox (2012). In our analysis, we instead compare two alternative policies that generate the same level of emissions by firm 1 . In this framework, carbon leak would be the ratio between the changes in emissions by the two firms under these two scenarios (indexed by $i$ ).

$$
\frac{\Delta e_{2}^{i}}{\left|\Delta e_{1}^{i}\right|}
$$

By definition the denominator is the same in either case. As such, our carbon leak measures essentially compares the changes in emissions by firm 2 under the two policy scenario, namely $\Delta e_{2, t}^{s i m}$ and $\Delta e_{2, s}^{s e q}$.

\subsection{The No Price Discrimination Model}

In the present sub-section, we shall analyze the case where each firm quotes the same price at home and abroad, although we do not rule out cost asymmetries. The general model in the next section allows firms to price discriminate across countries so that each firm chooses two prices, although in order to simplify we shall then impose symmetric costs.

Since no price discrimination is possible and no transportation cost exists, the two countries can be viewed as a single market with $A=B=M$, and total demand to firm 1 and 2 can be defined as $q_{i}\left(p_{i}, p_{j}\right)=2\left(M+\gamma p_{j}-p_{i}\right)$, for $i=1,2, i \neq j$. In order to simplify the exposition, and since profit maximization is not affected, we rescale demand and write it as ${ }^{10}$

$$
q_{i}\left(p_{i}, p_{j}\right)=M+\gamma p_{j}-p_{i}, \quad \text { for } i=1,2, i \neq j .
$$

\footnotetext{
9 Our emission standard policy differs from an intensity standard policy, as the regulation target is the total level of emissions $s$ rather the unitary polluting content $\beta$.

10 Rescaling demand is neutral as long as profit functions are rescaled, too. Here, instead, only revenues are rescaled. Still, this has no consequences on our results as quantities, marginal costs and tax rates are not directly compared across specifications of our model.
} 
The cost functions are $C_{i}\left(q_{i}\right)=c_{i} q_{i}$, for $i=1,2$ and with $c_{i}<M$. The best reply functions in the game where no policies are adopted by either country are

$$
p_{i}=(1 / 2)\left(M+c_{i}+\gamma p_{j}\right) \quad \text { for } i, j=1,2 .
$$

The Nash equilibrium prices are easily derived as:

$$
p_{i}^{*}=\left[M(2+\gamma)+2 c_{i}+\gamma c_{j}\right] /\left(4-\gamma^{2}\right), \text { for } i \neq j, \text { and } i, j=1,2 .
$$

Total quantities produced by each firm in the unregulated equilibrium are

$$
q_{i}^{*}=\left[\left(M(2+\gamma)-c_{i}\left(2-\gamma^{2}\right)+\gamma c_{j}\right)\right] /\left(4-\gamma^{2}\right) .
$$

so that total quantity, $Q^{*}=q_{1}^{*}+q_{2}^{*}=\left[2 M-\left(c_{1}+c_{2}\right)(1-\gamma)\right] /(2-\gamma)$.

Finally, the equilibrium profits are $\pi_{1}^{*}=\left(q_{1}^{*}\right)^{2}$ and $\pi_{2}^{*}=\left(q_{2}^{*}\right)^{2}$.

\subsubsection{Emission Standards}

Assume that the Government in the Home country sets an emission standard such that $\beta q_{1}<$ $\theta$, where $\theta$ is the desired emission level. Then we assume that, after the standard has been fixed, the price game unfolds in two stages. At stage 1 the unregulated firm 2 sets its price; at stage 2 firm 1, having observed firm 2's choice, also sets its price. This game is the simplest structure that allows the change we have in mind and this is the one we retain.

Solving backward, one can consider the second stage where firm 2 has set a price $p_{2}$ at the first stage. Then, the best reply by firm 1 is the best price in the set $P\left(p_{2} ; \theta\right)$ of $p_{1}$ values satisfying the constraint. Given the information provided by the first price, the constraint forces firm 1 to set a price high enough so that demand for its product satisfies the constraint $\beta q_{1}\left(p_{1}, p_{2}\right) \leq s$ or $\beta\left(M+\gamma p_{2}-p_{1}\right) \leq s$. This can be rewritten as $p_{1} \geq M+\gamma p_{2}-\theta$, where $\theta \equiv s / \beta$ is a convenient notation for the regulated output. As part of the policy one can assume that an output exceeding $s / \beta$ can only be produced with the additional cost of a penalty on emissions. We shall assume this penalty to be high enough to make it worthwhile for the firm to respect the target at equilibrium - otherwise the policy design would fail. The level of $s$ (or of $\theta$ ) here must be such that $\theta<q_{1}^{*}$ where $q_{1}^{*}$ is defined by (6) and corresponds to optimal output under no regulation. The penalty $w$ is assumed to be a function of emissions in excess of $s$, namely $w(e)=k+\omega(e-s)$, where $k>0$ is a fixed part of the penalty and $e=\beta q_{1}$. Let the function $B^{u}\left(p_{2}\right)=\left(M+c_{1}+\gamma p_{2}\right)(1 / 2)$ denote the unconstrained best reply for firm 1 when no policy is implemented. $B^{u}\left(p_{2}\right)$ is a linear function of $p_{2} \cdot{ }^{11}$ Therefore, the profit maximization program for firm 1 respecting the emission target is modified as

$$
\max _{p_{1}}\left(p_{1}-c_{1}\right)\left(M+\gamma p_{2}-p_{1}\right) \quad \text { s.t. } M+\gamma p_{2}-p_{1} \leq \theta
$$

The maximization program if the firm exceeds the constraint is

$$
\max _{p_{1}}\left(p_{1}-c_{1}\right) \theta+\left(p_{1}-c_{1}-\omega\right) q\left(p_{1}, p_{2}, \theta\right)-k
$$

where the function $q($.$) is defined as q\left(\theta, p_{2}, p_{1}\right)=\max \left[\left(M+\gamma p_{2}-p_{1}-\theta\right), 0\right]$.

The best reply for firm 1 when it violates the constraint and pays the penalty lies along the best reply of firm 1 under a simple tax on emissions, given by $B\left(p_{2}, \omega\right)=B^{u}\left(p_{2}\right)+(\beta \omega) / 2$,

11 If the exogenous level of emissions $s$ is such that $M-(s / \beta)<(1 / 2)\left(M+c_{1}\right)$, or $M-c_{1}<2 \theta$, then the constraint expressed as the function $p_{1}=C\left(p_{2}\right) \equiv M+\gamma p_{2}-\theta$ crosses from below the function $B^{u}\left(p_{2}\right)$, at the value $\bar{p}_{2}=\left(2 \theta-M+c_{1}\right) / \gamma$. Otherwise, if $M-c_{1}>2 \theta$, the constraint lies above the function $B^{u}\left(p_{2}\right)$ for all $p_{2}>0$, but the algebra would not be altered. 


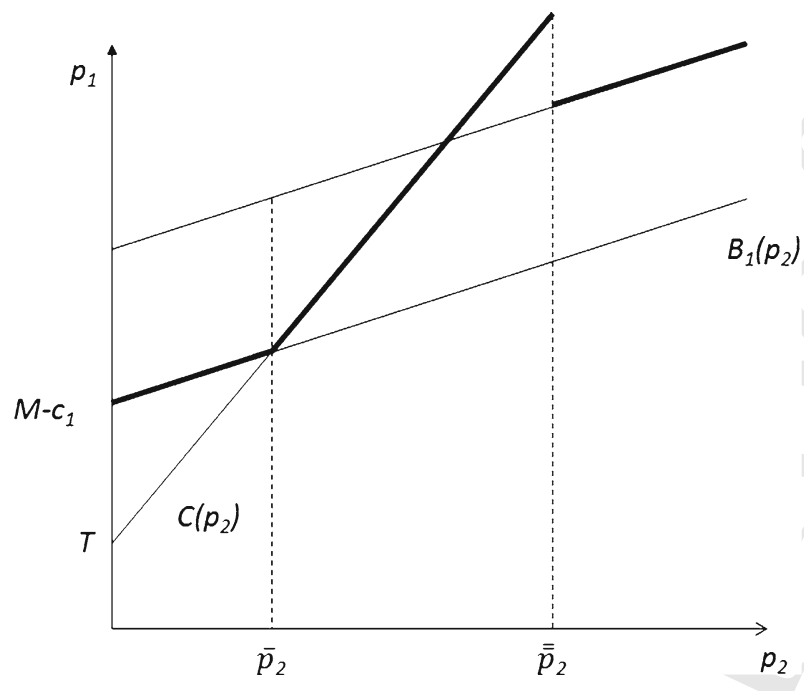

Fig. 1 Constrained optimization

where the tax rate would be $\omega$. The constraint crosses this line at the point with horizontal coordinate $\overline{\bar{p}}_{2} \equiv\left(2 \theta-M+c_{1}+\beta \omega\right) / \gamma$. However, firm 1 will adopt this reply function only for a price by firm 2 above $\overline{\bar{p}}_{2}$ as it shall be clarified shortly.

Hence the best reply for firm 1, considering also the constrained part, is

$$
C B\left(p_{2}\right)= \begin{cases}B^{u}\left(p_{2}\right)=(1 / 2)\left(M+c_{1}\right)+(\gamma / 2) p_{2} & \text { for } 0 \leq p_{2} \leq \bar{p}_{2} \\ C\left(p_{2}\right)=M+\gamma p_{2}-\theta & \text { for } \bar{p}_{2}<p_{2}<\overline{\bar{p}}_{2}+\eta \\ B\left(p_{2}, \omega\right)=(1 / 2)\left(M+c_{1}+\beta \omega\right)+(\gamma / 2) p_{2} & \text { for } \overline{\bar{p}}_{2}+\eta<p_{2} .\end{cases}
$$

The functions $B^{u}\left(p_{2}\right), B\left(p_{2}, \omega\right)$ and the constraint $C\left(p_{2}\right)$ are represented in Fig. 1 below, for the case where $M-c_{1}<2 \theta$, where in the graph, $T=M-\theta$. The constrained best reply $C B\left(p_{2}\right)$ is a piecewise linear function represented as the thick line with a kink at the point $\bar{p}_{2}$ and a discontinuity at the point $\overline{\bar{p}}_{2}+\eta .{ }^{12}$ The admissible values for $p_{1}$ satisfying the constraint depend upon the policy measure, $\theta$, and upon $p_{2}$. The idea here is that firm 1 , when its unconstrained best reply, $B\left(p_{1}\right)$, leads to a penalty for over-emissions, will choose $p_{1}$ so as to satisfy the constraint exactly.

We shall assume that the constraint be binding, least the policy would fail its objective in terms of emissions in the home country. Firm 2 acts, de facto, as a Stackelberg leader choosing $p_{2}$ knowing that $p_{1}$ shall be set so as to satisfy the constraint. Hence the maximization problem for firm 2 is

$$
\max _{p_{2}}\left(p_{2}-c_{2}\right)\left(M+\gamma\left(M+\gamma p_{2}-\theta\right)-p_{2}\right) .
$$

The profit maximizing price for 2 is

$$
\hat{p}_{2}=\left[M(1+\gamma)-\theta \gamma+c_{2}\left(1-\gamma^{2}\right)\right] /\left(2-2 \gamma^{2}\right)
$$

12 Firm 1 does not switch to the best reply $B\left(p_{1}\right)+\beta \omega / 2$ for a price $p_{2}=\overline{\bar{p}}_{2}$ because of the fixed part in the penalty, $k$. It would do so only if $k$ was equal to zero.

\section{Springer}


and $p_{1}$ is determined by the constraint as $p_{1}=M+\gamma \hat{p}_{2}-\theta$ or

$$
\hat{p}_{1}=\frac{M\left(2+\gamma-\gamma^{2}\right)-\theta\left(2-\gamma^{2}\right)+\gamma c_{2}\left(1-\gamma^{2}\right)}{2\left(1-\gamma^{2}\right)} .
$$

Under the standard, equilibrium production by firm 2 is given by

$$
q_{2, s}^{s e q}=(1 / 2)\left[M(1+\gamma)-c_{2}\left(1-\gamma^{2}\right)-\gamma \theta\right]
$$

where it is useful to take note that $-q_{2, s}^{s e q} / d \theta=\gamma / 2$. Obviously, setting $\theta=0$ in $q_{2, s}^{\text {seq }}$ does not give the unregulated equilibrium quantity as the quantity $q_{2, s}^{s e q}$ is computed using a Stackelberg solution. Total production is $Q_{s}^{s e q}=q_{1, s}^{s e q}+q_{2, s}^{s e q}=\theta+q_{2, s}^{s e q}$, or

$$
Q_{s}^{s e q}=(1 / 2)\left[M(1+\gamma)+\theta(2-\gamma)-c_{2}\left(1-\gamma^{2}\right)\right] .
$$

The quantity (and emissions) produced in country $\mathrm{F}$ increases by the amount $\Delta e_{2, s}^{s e q}=$ $q_{2, s}^{s e q}-q_{2}^{*}$, where $q_{2}^{*}$ is given by Eq. (6).

Therefore, the change in emissions in country 2 is

$$
\Delta e_{2, s}^{s e q}=\gamma \frac{M(1-\gamma)}{2(2-\gamma)}+\gamma \frac{\gamma c_{2}\left(3-\gamma^{2}\right)-2 c_{1}}{2\left(4-\gamma^{2}\right)}-\frac{\theta \gamma}{2},
$$

for $\gamma$ tending to zero $\Delta e_{2, s}^{s e q}$ goes to zero. Further, one can show that for reasonable differences in marginal costs, the change in production and hence in emissions by firm 2 is negative for a wide range of values for $s$ and therefore for $\theta$ : a negative leakage implies that policy in country $\mathrm{H}$ has a positive spillover in terms of global emission reduction. For instance, set $c_{1}=c_{2}=0$; recalling then that the unregulated output for the home firm is $q_{1}^{*}=M /(2-\gamma)$, Eq. (9) implies $\Delta e_{2, s}^{s e q} \geq 0$ only if $M(2-\gamma)>\theta(1-\gamma)$ or $\theta / q_{1}^{*} \leq(1-\gamma)$. Since $\theta=s / \beta$ is the domestic firm output level that satisfies the emission standard exactly, this condition is easily violated. Therefore, an emission standard is unlikely to lead to leakages in our model; in particular leakages occur only if the emission reduction required is relatively small and the substitutability parameter, $\gamma$, is low or $\gamma \leq 1-\theta / q_{1}^{*} .{ }^{13}$ These considerations shall be summarized after a comparison with a tax policy is completed.

We shall compare the change in emissions under a standard with the carbon leak obtained under the carbon tax-levied only on firm 1-which provides an emission reduction exactly equal to a given standard policy $s$.

\subsubsection{Competition Under a Carbon Tax}

We shall now assume that on each unit of emission produced by firm 1 the government in country $\mathrm{H}$ levies a tax equal to $t_{e}$, so that the marginal cost of firm 1 raises to $\beta t_{e}$. No other restriction is imposed. The profit maximization program for firm 1 results in the best reply function given in (8), where $c_{1}$ must be replaced by $c_{1 t} \equiv c_{1}+\beta t_{e}$. The equilibrium prices and quantities can be easily derived by appropriately rewriting the solutions in (5) and the following equations. Letting $t \equiv \beta t_{e}$, the equilibrium quantity by firm 1 in particular is given as a function of $t, q_{1, t}^{\text {sim }}=\left[M(2+\gamma)-c_{1 t}\left(2-\gamma^{2}\right)+\gamma c_{2}\right]\left(4-\gamma^{2}\right)^{-1}$. It is sufficient to

13 To relate the inequality to real world policy considerations, consider a $10 \%$ reduction in the domestic firm output: namely consider $\theta \leq 0.9 q_{1}^{*}$, where $\theta=q_{1, s}^{s e q}$ is implied by the desired level of emissions; then $\Delta e_{2, s}^{s e q} \geq 0$ only if $\gamma \leq 0.1$, that is, only if substitutability is extremely low. 
set this quantity equal to $s / \beta$ in order to find $t(s)$, the tax that brings forth an equilibrium quantity of emissions equal to $s$. The solution is the "equivalent carbon tax":

$$
\hat{t}=t_{e} \beta=\frac{M(2+\gamma)}{\left(2-\gamma^{2}\right)}+\frac{\left(\gamma c_{2}-\theta\left(4-\gamma^{2}\right)\right)}{\left(2-\gamma^{2}\right)}-c_{1}
$$

It is immediate to see that $\hat{t}$ is a function of $\theta$ (namely of the desired emission target $s$ ), and it is positive as far as the limit on emissions is binding, namely as far as $\beta q_{1, t}^{\text {sim }}>s$ (or equivalently $q_{1, t}^{\operatorname{sim}}>\theta$ ). It is therefore straightforward to compute the Nash equilibrium, using (6), with $c_{1}$ replaced by $c_{1 t}=\left(c_{1}+\hat{t}\right) .{ }^{14}$ Since $d q_{2, \hat{t}}^{s i m} / d c_{1 t}=\gamma /\left(4-\gamma^{2}\right)$ one has that

$$
-\frac{d q_{2, \hat{t}}^{\operatorname{sim}}}{d \theta}=-\frac{d q_{2}(t)}{d c_{1 t}} \frac{d \hat{t}}{d \theta}=\frac{\gamma}{2-\gamma^{2}} .
$$

An increase in the reduction $q_{1}^{*}-\theta$ (a reduction in $\theta$ ) brings forth an increase in production abroad. Hence there is a leakage of emissions abroad whenever a reduction in emission is obtained through a carbon tax. Indeed,

$$
\Delta e_{2, \hat{t}}^{\operatorname{sim}}=\frac{\gamma\left(M(\gamma+2)-c_{1}\left(2-\gamma^{2}\right)+\gamma c_{2}-\theta\left(4-\gamma^{2}\right)\right)}{\gamma^{4}-6 \gamma^{2}+8}
$$

which is always positive for all the admissible values of $\theta$.

Moreover, it is worth noting that the price of the unregulated firms when the standard is implemented in the regulated country is greater than the price of the underegulated firm whenever a carbon tax is introduced in the Home country, namely $p_{2, s}^{\text {seq }}>p_{2, t}^{\text {sim }}{ }^{15}$

14 As expressed above, the quantity of firm 1 as a function of $t(\theta)$ is given by $q_{1, t}^{\text {sim }}=$ $\left[M(2+\gamma)-c_{1 t}\left(2-\gamma^{2}\right)+\gamma c_{2}\right]\left(4-\gamma^{2}\right)^{-1}$. Similarly, the quantity of firm 2 is

$$
q_{2, t}^{\text {sim }}=\left(M(2+\gamma)-c_{2}\left(2-\gamma^{2}\right)+\gamma c_{1 t}\right)\left(4-\gamma^{2}\right)^{-1}
$$

For $t=\hat{t}$, quantities are

$$
q_{1, \hat{t}}^{\text {sim }}=\theta \quad q_{2, \hat{i}}^{\text {sim }}=\left(M(1+\gamma)-\gamma \theta-c_{2}\left(1-\gamma^{2}\right)\right)\left(2-\gamma^{2}\right)^{-1} .
$$

and prices become

$$
p_{1, \hat{t}}^{s i m}=\left(M\left(2+\gamma-2 \theta-\gamma c_{2}\right)\right)\left(2-\gamma^{2}\right)^{-1} \quad q_{2, \hat{t}}^{s i m}=\left(M\left(1+\gamma-\gamma \theta+c_{2}\right)\right)\left(2-\gamma^{2}\right)^{-1} .
$$

15 Recalling that $p_{2, s}^{\text {seq }}=\frac{M(1+\gamma)-\gamma \theta}{2\left(1-\gamma^{2}\right)}$ and that $p_{2, t}^{\text {sim }}=\frac{M(2+\gamma)+\gamma t}{4-\gamma^{2}}$, and assuming for simplicity that $c_{1}=c_{2}=0$, it is immediate to conclude that $p_{2, s}^{\text {seq }}-p_{2, \hat{t}}^{\text {sim }}=\frac{1}{2} \gamma^{2} \frac{M+M \gamma-\theta \gamma}{\gamma^{4}-3 \gamma^{2}+2}>0$.

\section{Springer}




\subsubsection{Comparison of Policies}

By comparing the increase in production in the foreign country under the two regimes, from Eqs. (9) and (10), we can state that the carbon leak under a carbon tax is larger than under an emission standard. ${ }^{16}$

Proposition 1 If price discrimination is not allowed (or firms sell in the same country), (i) a standard policy that reduces emissions by the regulated firm to a target level s entails a lower carbon leak than an equivalent carbon tax $t$. (ii) Further, an emission standard can lead to a reduction of pollution by the unregulated firm (negative leak); for instance, for equal marginal costs set to zero, this holds for any targeted emission level above $50 \%$ of the unregulated equilibrium emissions in the home country.

The following Proof proves part (ii).

Proof The $\Delta e_{2, s}^{s e q}$ value in (9) is positive if $\left(2-\gamma-\gamma^{2}\right) M+\left(3-\gamma^{2}\right) c_{2}-2 c_{1}-4 \theta+\theta \gamma^{2}$ is positive. Letting $\theta=\lambda M$ for $0<\lambda<1$, the condition is $\left(2-\gamma-\gamma^{2}-4 \lambda+\lambda \gamma^{2}\right) M+$ $\left(3-\gamma^{2}\right) c_{2}-2 c_{1}>0$. For instance then, with $c_{1}=c_{2}=0$ the expression is positive only if $2-\gamma(1+\gamma)>\lambda\left(4-\gamma^{2}\right)$. Hence if $c_{1}=c_{2}=0$, the leak is negative if $\lambda>$ $[2-\gamma(1+\gamma)] /\left(4-\gamma^{2}\right) \equiv \lambda^{\prime}(\gamma)$, and positive if $\lambda<\lambda^{\prime}(\gamma)$, where it can be noted that $\lambda^{\prime}(\gamma)$ is lower than $1 / 2$ for all $\gamma \geq 0$.

Hence, according to Proposition 1, a carbon tax makes the regulated firm less competitive in the usual sense; its best reply function in the Bertrand game shifts upward as if the firm had incurred a marginal cost increase. Its equilibrium output decreases while that of the foreign firm increases. By contrast, under an emission standard the regulated firm is made less competitive in a different way: it cannot use its price as it would like to do in a Bertrand simultaneous game, and it must instead use it as a tool to reduce its output in response to the price set by the competitor. In a sense the latter is then able to gain in value terms without a large increase in volumes in this second scenario.

Remark 1 A unilateral carbon tax can lead to an increase in global emissions. More precisely, if price discrimination is impossible, a reduction in emissions at home leads to higher global emissions if and only if $\beta<\gamma /\left(2-\gamma^{2}\right){ }^{17}$

$\overline{16}$ With the difference in leakages under the two regimes amounting to

$$
\Delta e_{2, \hat{t}}^{s i m}-\Delta e_{2, s}^{s e q}=\frac{\gamma^{2}}{2\left(2-\gamma^{2}\right)}\left(\left(M-c_{2}(1-\gamma)\right)(1+\gamma)+\gamma \theta\right)
$$

which is always positive since $M>c_{2}$ is necessary for the model to make sense.

17 Recalling that $s$ is the policy instrument, the total effect of $s$ on global emissions can be decomposed into the effect at home and abroad, that is

$$
\frac{d e}{d s}=\frac{d e_{1}}{d s}+\frac{d e_{2}}{d s}=\frac{d \tilde{c}_{1}}{d s}\left[\frac{\gamma}{4-\gamma^{2}}-\beta \frac{2-\gamma^{2}}{4-\gamma^{2}}\right]
$$

where $\tilde{c}_{1}=c_{1}+\beta t_{e}$. Since, obviously, $\frac{d \tilde{c}_{1}}{d s}<0$, it is easy to see that the total effect is negative if and only if $\left(\frac{\gamma}{4-\gamma^{2}}\right)-\beta\left(\frac{2-\gamma^{2}}{4-\gamma^{2}}\right)>0$ 


\subsection{Sequential Game Under a Carbon Tax}

We analyze, for the sake of completeness, a sequential game under a carbon tax, where the foreign firm is a Stackelberg leader, in order to perform a robustness check. The best reply for the home firm is $p_{1}\left(p_{2}, t\right)=\left(M+c_{1}+t\right) / 2+(\gamma / 2) p_{2}$ where $t$ is the carbon tax. The maximization program for the Stackelberg leader firm 2 is then:

$$
\max _{p_{2}}\left(p_{2}-c_{2}\right)\left(M+\gamma p_{1}\left(p_{2}, t\right)-p_{2}\right)
$$

with solution $p_{2, t}^{\text {seq }}=\frac{M(2+\gamma)+c_{2}\left(2-\gamma^{2}\right)+\gamma\left(t+c_{1}\right)}{4-2 \gamma^{2}}$. After computing the value of $p_{1}$ one can obtain the equilibrium quantities ${ }^{18}$ for a generic tax $t$ and then solve for the equivalent tax namely for $\tilde{t} \equiv t_{e} \beta$, such that $q_{1, \tilde{t}}^{\text {seq }}=\theta$. This value is found to be

$$
\tilde{t}=\xi\left[\left(4 \gamma^{2}-8\right) \theta+M\left(4+2 \gamma-\gamma^{2}\right)+\left(2-\gamma^{2}\right) \gamma c_{2}\right]-c_{1}
$$

where $\xi=\left(4-3 \gamma^{2}\right)^{-1}$.

The final prices under the equivalent tax are

$$
\begin{aligned}
& p_{1, \tilde{t}}^{s e q}=\xi\left[M\left(4+2 \gamma-\gamma^{2}\right)-\left(4-\gamma^{2}\right) \theta+\left(2-\gamma^{2}\right) \gamma c_{2}\right] \\
& p_{2, \tilde{t}}^{s e q}=\xi\left[M(2+2 \gamma)+\left(2-\gamma^{2}\right) c_{2}-2 \theta \gamma\right] .
\end{aligned}
$$

The corresponding quantities are:

$$
\begin{aligned}
& q_{1, \tilde{t}}^{\text {seq }}=\theta \\
& q_{2, \tilde{t}}^{\text {seq }}=\xi\left(2-\gamma^{2}\right)\left(M-c_{2}+M \gamma-\theta \gamma+\gamma^{2} c_{2}\right)
\end{aligned}
$$

The comparison of the foreign firm production under a sequential game carbon tax scenario and the quantity under an emission standard shows that, again, the carbon leak is higher under a carbon tax, confirming the results obtained with different game structures.

Indeed $q_{2, s}^{s e q}=(1 / 2)\left(M(1+\gamma)-c_{2}\left(1-\gamma^{2}\right)-\gamma \theta\right)$ and

$$
q_{2, \tilde{t}}^{s e q}-q_{2, s}^{s e q}=(\eta / 2) \gamma^{2}\left(M(1+\gamma)-c_{2}\left(1-\gamma^{2}\right)-\theta \gamma\right) .
$$

This difference is positive for $\gamma \in[0,1)$. This robustness check clearly shows that the standard leads the unregulated firm 2 to set a higher price than under the equivalent carbon tax; this less aggressive behavior is induced by the quantity cap on the domestic output under the emission standard. Indeed a comparison reveals that the difference between the prices in a sequential game under a standard, computed in 2.2.1, and the prices under the sequential tax game are both positive ${ }^{19}$, namely $p_{i, s}^{s e q}-p_{i, \tilde{t}}^{s e q}>0$ for $i=1,2$. This difference confirms the intuition discussed in the Introduction that the standard restricts the home firm's best reply more than a tax, even when firm 2 retains its ability to manipulate the rival's price.

\subsection{The Simultaneous Game Under a Standard}

Suppose that firm 1 acts in the expectation that firm 2 will use its best reply, then firm 1 will choose the price $p_{1}$ solving $p_{1}=M+\gamma p_{2}-\theta$ while at the same time $p_{2}=\left(M+\gamma p_{1}+c_{2}\right) / 2$.

\footnotetext{
18 One has $q_{2, t}^{\text {seq }}=\frac{M(2+\gamma)-c_{2}\left(2-\gamma^{2}\right)+\gamma\left(c_{1}+t\right)}{4}$ and $q_{1, t}^{s e q}=\frac{M\left(4+2 \gamma-\gamma^{2}\right)-\left(4-3 \gamma^{2}\right)\left(t+c_{1}\right)+\gamma c_{2}\left(2-\gamma^{2}\right)}{4\left(2-\gamma^{2}\right)}$.

19 Indeed, $p_{1, s}^{s e q}-p_{1, \tilde{t}}^{s e q}$ is equal to $(h / v) \gamma^{3}$ and $p_{2, s}^{s e q}-p_{2, \tilde{t}}^{s e q}$ is equal to $(h / v) \gamma^{2}$ where $h=$ $\left(M+\gamma(M-\theta)-c_{2}\left(1-\gamma^{2}\right)\right)$ and $v=\left(1-\gamma^{2}\right)\left(4-3 \gamma^{2}\right)$ are both positive for $\gamma$ in $[0,1)$.
}

\section{Springer}


These two equations uniquely define the pair $\left(p_{1, s}^{\text {sim }}, p_{2, s}^{\text {sim }}\right)$ satisfying the constraint and lying on the best reply function of firm 2. Since the solution obtained under a tax scheme in Sect. 2.2.2 also lies on the best reply of firm 2 , it must be that the unique tax $\hat{t}$ that achieves a demand to firm 1 equal to $\theta$ must lead to prices equal to $\left(p_{1, \hat{t}}^{\operatorname{sim}}, p_{2, \hat{t}}^{\operatorname{sim}}\right)=\left(p_{1, s}^{\operatorname{sim}}, p_{2, s}^{\operatorname{sim}}\right)$ as can be easily verified by computation. It follows that $p_{1, s}^{\operatorname{sim}}=\left[M(2+\gamma)+\gamma c_{2}-2 \theta\right]\left(2-\gamma^{2}\right)^{-1}$ and $p_{2, s}^{s i m}=\left[M(1+\gamma)+c_{2}-\gamma \theta\right]\left(2-\gamma^{2}\right)^{-1}$ (with $\left.p_{1}^{e}>p_{2}^{e}\right)$. The corresponding quantities are $q_{1, s}^{\text {sim }}=\theta$ and $q_{2, s}^{\text {sim }}=\frac{M(1+\gamma)-c_{2}\left(1-\gamma^{2}\right)-\gamma \theta}{2-\gamma^{2}}=q_{2, \hat{t}}^{\text {sim }}$.

The emissions by the foreign firm (and hence the carbon leak) are the same under a tax as under a standard if prices are set simultaneously with firm 2 using its best reply function and firm 2 setting a price equal to the price that respects the constraint.

As discussed above, this solution is only apparently stable, because a deviation [in particular the "best deviation"] by firm 2 must lead to a change in the price by firm 1 in order to respect the constraint. The best deviation for firm 2 is to the price computed as a solution of the Stackelberg game given above, with $p_{2, s}^{\text {seq }}=\left[M(1+\gamma)+c_{2}\left(1-\gamma^{2}\right)-\gamma \theta\right] /\left(2-2 \gamma^{2}\right)$. If firm 1 sticks to $p_{1, s}^{\text {sim }}$ then $q_{1}\left(p_{1, s}^{\text {sim }}, p_{2, s}^{\text {seq }}\right)$ exceeds $\theta$ as it can be easily verified. ${ }^{20}$ Hence the price $p_{2, s}^{s i m}$ is not admissible once firm 2 chooses $p_{2, s}^{\text {seq }}$ (it does not belong to $P\left(p_{2, s}^{\text {seq }}\right)$ ). In this sense the solution with simultaneous moves is upset by such a deviation by firm 2 .

Under price competition with differentiated products, for any sequence of moves, prices are strategic complements, and the marginal benefit of a price increase for firm $\mathrm{i}$ is an increasing function of the rival's price. An increase in one's own price reduces one's own demand, but this negative effect is dampened because the rival also increases its price along its best reply function. The steeper the rival's best reply the stronger is this dampening effect. Hence, the steeper the rival's best reply the higher the marginal benefit of a price increase. Assume now to start an unregulated market. Then the equilibrium prices are determined in a simultaneous Bertrand game. The effect of a tax that leads to the desired level of emissions at home is to shift the best reply of the taxed firm (parallel to the original one) so as to increase both firms' prices. This new equilibrium has firm 1 producing the quantity that must be consistent with the Government fixed emission target. Under an emission standard for the same target, if firms play simultaneously the best reply of firm 2 is untouched while that of firm 1 is not the same as under a tax, but is as represented in our Fig. 1 and displays a higher slope in the relevant range. However, the tax was set so as to respect the constraint and therefore the equilibrium price pair was represented by a point lying on firm 1 constraint: the equilibrium is therefore unchanged and the two policies produce the same prices-quantities. Under a standard and sequential play with 2 as a leader, the equilibrium prices are moved in the upward direction by the ability of firm 2 to choose a price that maximizes its own profit along the constraint for firm 1 and away from firm 2 best reply function. As prices go up the quantity of firm 1 is fixed (since it is given by the constraint or by the equivalent tax) and that of firm 2 decreases. Finally, price leadership by firm 2 under a tax leads to higher prices than a tax with simultaneous play, but still lower than under a standard and price leadership; consider that an equivalent tax for this case is not the same as for the case with simultaneous play since the equilibrium prices are determined by different formulas. Therefore, the two different taxes produce different amounts of leakage.

\footnotetext{
20 Indeed $q_{1}\left(p_{1, s}^{s i m}, p_{2, s}^{\text {seq }}\right)=\frac{\left(4 \theta+M \gamma^{3}+M \gamma^{4}-6 \theta \gamma^{2}+\theta \gamma^{4}-\gamma^{3} c_{2}+\gamma^{5} c_{2}\right)}{2\left(\gamma^{4}-3 \gamma^{2}+2\right)}$, while $q_{1}\left(p_{1, s}^{s i m}, p_{2, s}^{\text {seq }}\right)-\theta=$ $\frac{\gamma^{3}}{2} \frac{M+\gamma(M-\theta)-c_{2}\left(1-\gamma^{2}\right)}{\gamma^{4}-3 \gamma^{2}+2}$ a positive quantity as far as $c_{2}<M$, a necessary condition for firm 2 being able to produce.
} 
In "Appendix I", we provide a table summarizing and comparing the resulting quantities and prices of all the different scenarios analyzed and discussed above.

\section{The Price Discrimination Model}

In this section, we assume again that there are two firms located in two different countries, the home and the foreign one respectively, and each firm can supply its product in both countries. ${ }^{21}$ Firms can now price discriminate across countries. Firm 1 quotes price $p_{1}^{h}$ for sales at home and $p_{1}^{f}$ for its exports to country $\mathrm{F}$ (similarly, firm 2 quotes price $p_{2}^{f}$ for sales in country $\mathrm{F}$ and $p_{2}^{h}$ for its exports to $\mathrm{H}$ ). Demand functions in the two countries are given by (1) and (2). Production and transport costs are assumed to be equal to zero, to simplify. ${ }^{22}$

When there are no emission restrictions in country $\mathrm{H}$, the two firms engage in price competition and the resulting equilibrium is symmetric. Prices are $p_{i}^{b h}=A /(2-\gamma)$ and $p_{i}^{b f}=B /(2-\gamma)$ and equilibrium demands are $q_{i}^{b h}=A /(2-\gamma)$ and $q_{i}^{b f}=B /(2-\gamma)$ for $i=1,2$, where the superscript $b$ refers to the baseline setting.

\subsection{Emission Standards Versus Carbon Tax}

We now assume that an emission standard is introduced in country $\mathrm{H}$ : as a consequence, total emissions by firm 1 in the regulated country cannot exceed $s$. Here, given the solution to the unconstrained competition game, the restriction on emissions $s$ bites only if $\beta(A+B) /(2-$ $\gamma)>s$, or

$$
\bar{\theta} \equiv(A+B) /(2-\gamma)>\theta .
$$

In a general form, the binding constraint for firm 1 is $q_{1}^{s h}+q_{1}^{s f}<\theta$, where superscript $s$ distinguishes the emission standard setting. The constraint can be written as $A+B+\gamma\left(p_{2}^{h}+\right.$ $\left.p_{2}^{f}\right)-p_{1}^{h}-p_{1}^{f}=\theta$ if it binds, so that it is apparent that it does not define the two prices set by firm 1 even if the prices by the foreign firm, $p_{2}^{f}$ and $p_{2}^{h}$ are given. This implies that Stackelberg leadership by firm 2 determines the position of the constraint but that firm 1 has some leeway in adjusting the prices domestically and abroad so as to maximize its profits along the constraint. The Lagrangian for firm 1 is

$$
\begin{aligned}
L\left(p_{1}^{h}, p_{2}^{f}, \lambda\right)= & \left(A-p_{1}^{h}+\gamma p_{2}^{h}\right) p_{1}^{h}+\left(B-p_{1}^{f}+\gamma p_{2}^{f}\right) p_{1}^{f} \\
& +\lambda\left(A+B-\theta+\gamma\left(p_{2}^{h}+p_{2}^{f}\right)-p_{1}^{h}-p_{1}^{f}\right)
\end{aligned}
$$

21 Production only takes place in country $\mathrm{H}$ for firm 1 and in country $\mathrm{F}$ for firm 2.

22 This framework could be also extended to analyze a 3-firm setting, with two symmetric firms located in the regulated country and one firm located in the unregulated country. The demand functions individually faced by each firm in the domestic country $\mathrm{H}$ are

$$
q_{1}^{h}=A+\gamma p_{3}+\beta p_{2}-p_{1} \quad q_{2}^{h}=A+\gamma p_{3}+\beta p_{1}-p_{2} \quad q_{1}^{h}=A+\gamma\left(p_{1}+p_{2}\right)-p_{3}
$$

Since firms 1 and 2, in the home country, are perfectly symmetric, they will be allowed to produce up to $50 \%$ of total emissions each. Since there is no trade in emission permits, the two firms will be charging exactly the same price, and the conclusions in terms of leakage and trade balance will be similar to those of the 2-by-2 setting.

\section{를 Springer}


The "Stackelberg follower" prices for firm 1 are

$$
\begin{aligned}
& p_{1}^{s h}=\frac{3 A+B-2 \theta}{4}+\frac{1}{4} \gamma p_{2}^{f}+\frac{3}{4} \gamma p_{2}^{h} \\
& p_{1}^{s f}=\frac{3 B+A-2 \theta}{4}+\frac{3}{4} \gamma p_{2}^{f}+\frac{1}{4} \gamma p_{2}^{h}
\end{aligned}
$$

Firm 2, acting as a Stackelberg leader, sets prices to maximize its profits, aware that firm 1 will abide the emission constraint. Its maximization program is

$$
\max _{p_{2}^{h}, p_{2}^{f}}\left(A+\gamma p_{1}^{s h}-p_{2}^{h}\right) p_{2}^{h}+\left(B+\gamma p_{1}^{s f}-p_{2}^{f}\right) p_{2}^{f}
$$

where $p_{1}^{s h}$ and $p_{1}^{s f}$ are as in (13). As a result, ${ }^{23}$ in equilibrium, total emissions in country $\mathrm{H}$ are $\beta \theta$ and in country $\mathrm{F}$ are equal to output produced by firm 2 , that is:

$$
e_{2}^{s}=q_{2}^{s}=(1 / 2)[(A+B)(1+\gamma)-\theta \gamma] .
$$

In accordance with the analysis in the baseline model, we need to determine the carbon leak when firm 1 is subject to either an emission standard or a carbon tax. After the introduction of a carbon $\operatorname{tax} t_{e}$ on firm 1, we solve for the Nash equilibrium prices, ${ }^{24}$ and find total equilibrium emissions as a function of $t=t_{e} \beta:^{25}$

$$
\beta q_{1}^{t}=\beta \frac{(A+B)(2+\gamma)-2 t\left(2-\gamma^{2}\right)}{4-\gamma^{2}} \quad \text { and } \quad q_{2}^{t}=\frac{(A+B)(2+\gamma)+2 t \gamma}{4-\gamma^{2}} \text {. }
$$

We assume that the government in country $\mathrm{H}$ introduces a tax $t$ such that total emissions by firm 1 will reach the desired level, that is $q_{1}^{t}=\theta$ - this desired tax level, $\bar{t}$, is the solution to $2\left(2-\gamma^{2}\right) \bar{t}=(2+\gamma)(A+B-\theta(2-\gamma))$.

Hence, total emissions with $t=\bar{t}$ (and hence, $t_{e}=\bar{t} / \beta$ ) are:

$$
\beta q_{1}^{t}+q_{2}^{t}=\beta \theta+((A+B)(1+\gamma)-\theta \gamma) /\left(2-\gamma^{2}\right),
$$

where subscript $t$ denotes the carbon tax scenario.

\subsection{Carbon Leak and Global Emissions}

It is now possible to compare the levels of carbon leak, as previously defined, to assess the change in emissions by firm 2 under the two alternative scenarios. ${ }^{26}$ Since obviously $\Delta q_{1}(t)=\Delta q_{1}(s)$, the difference in global emissions under the two policies is:

$$
q_{2}^{t}-q_{2}^{s}=(\gamma / 2)((A+B)(1+\gamma)-\theta \gamma) /\left(4-2 \gamma^{2}\right) .
$$

23 See "Appendix II" for the formal derivation.

24 With firm 1 problem defined by:

$$
\max _{p_{1}^{h}, p_{1}^{f}}=\left(p_{1}^{h}-t\right) q_{1}^{h}\left(p_{1}^{h}, p_{2}^{h}\right)+\left(p_{1}^{f}-t\right) q_{1}^{f}\left(p_{1}^{f}, p_{2}^{f}\right) .
$$

25 See "Appendix II" for further details.

26 By definition, the change in emission by firm 1 is 0 . 
Also, the differences in production with respect to the baseline model by firm 2 under a tax and under a standard are

$$
\begin{aligned}
& \Delta q_{2}(s)=\gamma \frac{(A+B)(1-\gamma)-\theta(2-\gamma)}{2(2-\gamma)} \\
& \Delta q_{2}(t)=\gamma \frac{(A+B-\theta(2-\gamma))}{(2-\gamma)\left(2-\gamma^{2}\right)} .
\end{aligned}
$$

Letting $\sigma=1-\theta / \bar{\theta}$, the numerator in (19) is positive if $\sigma>\gamma$, while the numerator in (20) is positive as far as $\sigma>0$. Hence an equivalent carbon tax always leads to leakages, while an emission standard can lead to a reduction in emissions abroad, in particular if goods exhibit a degree of substitutability not lower than the percentage required reduction in emissions - this looks as a very mild condition indeed, if one considers realistic orders of magnitude for admissible percentage reductions.

Proposition 2 When international price discrimination is allowed, the carbon leak under a tax policy is larger than under an emission standard. The difference between the two policies increases with the degree of substitution between the foreign and domestic goods. In fact, if product differentiation is high, an emission standard may give rise to a negative leakage (a reduction in emissions in country $F$ ).

This result confirms the comparison obtained when price discrimination is not allowed.

Consider now the change in global emissions: under a standard policy, the change is negative if $\Delta q_{2}(s)+\beta \Delta q_{1}<0$, where $\Delta q_{2}(s)$ is given by (19) and where $\Delta q_{1}$ is the same under the two policies, namely equal to $\beta(\theta-(A+B) /(2-\gamma)) .{ }^{27}$ One can easily show that a standard never induces higher global emissions.

Under a tax policy, by contrast, one has that the global change in emissions is negative if $\Delta q_{2}(t)+\beta \Delta q_{1}<0$ where $\Delta q_{2}(t)$ is given by (20). The expression for the change in global emissions then becomes

$$
\Delta q(t)=\gamma \frac{A+B-\theta(2-\gamma)}{(2-\gamma)\left(2-\gamma^{2}\right)}+\beta\left(\theta-\frac{A+B}{2-\gamma}\right),
$$

or, letting $\omega^{-1}=(2-\gamma)\left(2-\gamma^{2}\right)$, one has

$$
\Delta q(t)=\omega[A+B-\theta(2-\gamma)]\left(\beta \gamma^{2}+\gamma-2 \beta\right)
$$

Since $\omega$ is positive and since the term $(A+B)-\theta(2-\gamma)$ is positive for the admissible levels of $\theta$, one has that a global reduction can be obtained only if $\gamma<\beta\left(2-\gamma^{2}\right)$. This last inequality can be violated for low values of $\beta$ and high values of $\gamma$. Hence, under these conditions, a carbon tax can induce higher global emissions.

Remark 2 If international price discrimination is allowed, an emission standard policy never leads to higher global emissions. An equivalent carbon tax leads to an increase in global emissions if the degree of product substitutability is high and the emission rate of the home firm is low enough, with the exact region given by the pairs $(\gamma, \beta)$ lying below the curve $\beta=\gamma /\left(1-\gamma^{2}\right)$.

27 Since after some manipulations this inequality can be written as

$$
(A+B)\left(2 \beta-\gamma+\gamma^{2}\right)>\theta\left(4 \beta-2 \gamma+\gamma^{2}-2 \beta \gamma\right),
$$

one only has to check whether this inequality could be violated for $\theta=\bar{\theta}$ [see Eq. (11)]. The inequality then is reduced to $\gamma^{2}(2-\gamma)>0$, which holds true as far as $\gamma>0$. 
This qualifies the validity of the result obtained in Sect. 2. The results for carbon leak and for global emissions hinge upon the underlying price adjustments: under either policy, both the domestic and the foreign firm prices increase; however, the price increase under a standard is higher than under a tax, with the corresponding decrease in the quantities produced and in particular by firm 2 , reducing the leakage.

\subsection{Trade Balance}

In this section, we quantify the trade gains/losses following the unilateral implementation of the environmental policy in country $\mathrm{H}$. We define the trade balance of country $\mathrm{H}$ as the difference in imported and exported quantities, that is $T B Q_{H}=q_{2}^{h}-q_{1}^{f} \cdot{ }^{28}$ To simplify, we assume that the two markets have equal size, that is $A=B=Z$; here the maximum value for $\theta$ becomes $\bar{\theta}=2 Z /(2-\gamma)$. The trade balance of the baseline setting is exactly equal to 0 under these parameter restrictions.

In the regulated country, the trade balance under a tax or an emission standard are, respectively, given by

$$
\begin{aligned}
& T B Q^{t}=\frac{(1+\gamma)((2-\gamma) \theta-2 Z)}{2\left(2-\gamma^{2}\right)} \\
& T B Q^{s}=(1 / 4)((2+\gamma) \theta-2(1+\gamma) Z)
\end{aligned}
$$

Since $T B Q^{t}$ is negative for $\theta<\bar{\theta}$, it is apparent that in the case of a carbon tax, the implementation of a unilateral environmental policy worsens the trade balance of the regulated country which becomes a net-importer for any value of $\gamma$.

In the case of a standard policy instead, the regulated country can become a net exporter, according to the value taken by $\theta$ : if this is close enough to the maximum, $\bar{\theta}$, the country becomes a net exporter. The exact range of values for $\theta$ for which this is the case is $2 Z(1+$ $\gamma) /(2+\gamma)<\theta<\bar{\theta}$ or $\theta$ in $(\tilde{\theta}(\gamma), \bar{\theta}(\gamma))$, where both the lower and upper bounds of the interval are increasing functions of $\gamma$. The gap $\bar{\theta}(\gamma)-\tilde{\theta}(\gamma)$ widens as $\gamma$ increases, namely as substitutability increases. In practical terms, even an important percentage reduction in emissions can be achieved while leading to an improvement in the trade balance in volumes, provided $\gamma$ is high enough - think of industries like cement, or steel. For instance, a simulation shows that $\gamma$ equal to 0.5 allows a percentage reduction of slightly more than $10 \%$ in emissions while guaranteeing an improvement in the trade balance.

Then, we take it that the effect of a tax on the trade balance is negative and that of a standard is positive - and, as it can be easily seen, in the extreme range of policies for which it is negative, less detrimental than that of a tax. ${ }^{29}$ The results can be summarized as follows.

Proposition 3 For any level of $\gamma$ in $(0,1)$, the trade balance of the regulated country worsens if a carbon tax is implemented. The trade balance under a carbon tax is always worse than under a standard.

${ }^{28}$ In "Appendix III", we also assess the impact of these unilateral policies on the net trade balance defined in terms of values.

${ }^{29}$ Recalling that $T B Q^{t}<0, \forall \gamma \in(0,1)$, the difference between the trade balance under the two different scenarios is

$$
T B Q^{s}-T B Q^{t}=\frac{\gamma^{2}}{4\left(2-\gamma^{2}\right)}(2 Z(1+\gamma)-\theta \gamma)
$$

which is positive for $\gamma<1$. 
The following Remark investigates the impact of an emission standard policy on the trade balance.

Remark 3 A standard can improve or deteriorate the trade balance: an improvement is more easily achieved the higher the degree of substitutability and the lower the target reduction in emissions.

\section{Conclusions}

This paper contributes to the existing literature on anti-pollution policies by comparing the effects, in terms of carbon leakages and trade flows, of two alternative policy instruments that can be unilaterally implemented by an industrialized country, namely a carbon tax and an emission standard policy. Carbon leakages (and job leakages) are an argument against environmental policies in the U.S. and other industrialized countries where some sectors are heavily exposed to competition from less developed countries. In general, leakages are a serious issue in evaluating the real effectiveness of anti-pollution policies at a global scale (e.g. Morgenstern 2009). They are also relevant at a national level when regulation is incomplete.

We analyze an international duopoly with price competition and differentiated products. We do not consider relocation of plants (which are medium or long-term decisions), but only production changes and the implied emissions. A carbon tax leads, as expected, to carbon leakages; furthermore, the carbon leak may be so large as to increase global emissions. An emission standard policy leads to a leak only under extreme conditions, namely for unlikely large targeted reductions, otherwise it causes a reduction of emissions abroad as well as at home. Interestingly, the home country then functions as a global regulator in this case. Of course we do not want to stress this particular result as it may be due to the specificity of our model, while the more general argument we propose is that emission standards are more effective than taxes in the presence of incomplete regulation and of oligopolistic price competition. The different effects of the two policies arise because, under an emission standard, the firm in the unregulated country can expect the regulated firm to abide to the regulation and therefore to abandon its unconstrained best reply function and raise prices in order to curtail production (and therefore emissions). This amounts to let the unregulated firm act as a Stackelberg leader in a two stage game. Under a tax, instead, firms behave as Bertrand competitors in the usual sense; the regulated firm, then, is only penalized as having a higher cost than without a tax.

We have considered two different scenarios: in the baseline one, firms are not discriminating between the two countries, and they charge the same price in the home and foreign country. In a more generalized version, we let instead both firms discriminate by charging two different prices. We measure the carbon leakage by the increase in production abroadwhich brings along an increase in emissions abroad hampering the global effectiveness of the antipollution policy. In either case, we observe that a greater carbon leakage occurs under a carbon tax. Under price discrimination, an increase in global emissions after a carbon tax cannot be ruled out (a result also obtained in Feddersen 2012). This, however, never occurs under an emission standard policy. In this sense, perverse results of environmental policies seem to be by far less likely under an emission standard than under a tax.

As to the effects on trade balance, in the two country framework, the carbon tax worsens the trade balance in volumes of the regulated country, while the standard policy leads to an improvement if the degree of substitution between the two goods is high enough (otherwise it leads to a worsening). Furthermore, a standard policy is always leading to better trade 
balance in volumes for the home country than an equivalent tax. If volumes are related to jobs in the regulated industry, then of course a standard may be preferred also considering the impact on employment levels.

Our analysis is cast in a partial equilibrium framework and as such it cannot fully incorporate all the effects of policy changes. For instance, in a multi-sector economy, a carbon tax may alter the equilibrium prices of the factors most used in the production of the "dirty" goods; if these factor prices decrease there is a reduction in costs for other sectors, and also possibly for the competing foreign firm. However Fullerton and Heutel (2007) in a general equilibrium model argue that with a carbon tax, "as pollution becomes more costly, the dirty sector seeks to adjust its demand for all three inputs", namely labor, capital, and emissions, but the changes are not as obvious as one may expect. In our model input price changes may alter the marginal costs. However, it is difficult to predict the final direction of change. A second issue is that of the so-called "second dividend" of a carbon tax. If revenues from a tax are used to reduce other distortionary taxes, like a tax on income, the final effect on welfare is increased Goulder (1995). However, we do not discuss welfare effects, but just effects on leakages and on the trade balance. The preference for a tax over an emission standard in terms of welfare may be clearly affected by the existence of a double dividend. Even in our analysis, if the Government can use the tax receipts to cut other pre-existing taxes on non-dirty inputs used by the domestic firm, or on its sales income, the final resulting negative effects of the tax on trade and on leakages may change.

\section{Appendices}

\section{I: Summary of Results}

Table 1 summarizes the main results obtained throughout our main analysis and extensions. ${ }^{30}$ The comparison of the different equilibria reveals that

$$
\begin{aligned}
& q_{1, s}^{s i m}=q_{1, s}^{s e q}=q_{1, \hat{t}}^{\text {sim }}=q_{1, \tilde{t}}^{s e q}=\theta \\
& q_{2, \hat{t}}^{\text {sim }}=q_{2, s}^{\text {sim }}>q_{2, \tilde{t}}^{\text {seq }}>q_{2, s}^{\text {seq }}
\end{aligned}
$$

and that

$$
p_{i, s}^{s e q}>p_{i, \tilde{t}}^{s e q}>p_{i, \hat{t}}^{s i m}=p_{i, s}^{s i m}
$$

for $i=1,2$.

Table 1 Summary of results

\begin{tabular}{lll}
\hline Policy instrument & Simultaneous game & Sequential game \\
\hline No regulation & $\left(q_{i}^{b}, p_{i}^{b}\right)$ with $i=1,2$ & \\
Standards & $\left(\left(q_{1, s}^{\text {sim }}, q_{2, s}^{\text {sim }}\right),\left(p_{1, s}^{\text {sim }}, p_{2, s}^{\text {sim }}\right)\right)$ & $\left(\left(q_{1, s}^{\text {seq }}, q_{2, s}^{\text {seq }}\right),\left(p_{1, s}^{\text {seq }}, p_{2, s}^{\text {seq }}\right)\right)$ \\
Equivalent carbon tax & $\left(\left(q_{1, \hat{t}}^{\text {sim }}, q_{2, \hat{t}}^{\text {sim }}\right),\left(p_{1, \hat{t}}^{\text {sim }}, p_{2, \hat{t}}^{\text {sim }}\right)\right)$ & $\left(\left(q_{1, \tilde{t}}^{\text {seq }}, q_{2, \tilde{t}}^{\text {seq }}\right),\left(p_{1, \tilde{t}}^{\text {seq }}, p_{2, \tilde{t}}^{\text {seq }}\right)\right)$ \\
\hline
\end{tabular}

30 The results and their comparisons discussed below rely on the simplifying assumption that $c_{1}=c_{2}=0$. 


\section{II: Derivation of Equilibrium in the $2 \times 2$ Model}

Let us consider the emission standard policy first. The Lagreangean for firm 1 is

$$
\mathcal{L}\left(p_{1}^{h}, p_{1}^{f}, \lambda\right)=q_{1}^{h} p_{1}^{h}+q_{1}^{f} p_{1}^{f}+\lambda\left(q_{1}^{h}+q_{1}^{f}-\theta\right)
$$

and the best reply is:

$$
\begin{aligned}
& p_{1}^{h}\left(p_{2}^{h}, p_{2}^{f}\right)=\frac{1}{4}\left(3 A+B-2 \theta+\gamma p_{2}^{f}+3 \gamma p_{2}^{h}\right) \\
& p_{1}^{f}\left(p_{2}^{h}, p_{2}^{f}\right)=\frac{1}{4}\left(A+3 B-2 \theta+3 \gamma p_{2}^{f}+\gamma p_{2}^{h}\right)
\end{aligned}
$$

Firm 2 then uses these best replies above to maximize

$$
\begin{aligned}
\pi_{2}= & q_{2}^{h} p_{2}^{h}+q_{2}^{f} p_{s}^{f} \\
= & p_{2}^{f}\left(\frac{1}{4} \gamma\left(A+3 B-2 \theta+3 \gamma p_{2}^{f}+\gamma p_{2}^{h}\right)+B-p_{2}^{f}\right) \\
& +p_{2}^{h}\left(\frac{1}{4} \gamma\left(3 A+B-2 \theta+\gamma p_{2}^{f}+3 \gamma p_{2}^{h}\right)+A-p_{2}^{h}\right) .
\end{aligned}
$$

The equilibrium price set by firm 2 in country $\mathrm{H}$ is

$$
p_{2}^{h, s}=\frac{A\left(-2 \gamma^{3}-3 \gamma^{2}+3 \gamma+4\right)+\gamma\left(B(\gamma+1)+\left(\gamma^{2}-2\right) \theta\right)}{4\left(\gamma^{4}-3 \gamma^{2}+2\right)},
$$

while $p_{2}^{f, s}$ is obtained by interchanging $A$ and $B$ in the expression for $p_{2}^{h, s}$. Finally, the equilibrium price of firm 1 in country $\mathrm{H}$ is given by

$$
p_{1}^{h, s}=\frac{A\left(3 \gamma^{4}-4 \gamma^{3}-13 \gamma^{2}+6 \gamma+12\right)+B\left(\gamma^{4}-3 \gamma^{2}+2 \gamma+4\right)-2\left(\gamma^{2}-2\right)^{2} \theta}{8\left(\gamma^{4}-3 \gamma^{2}+2\right)}
$$

while $p_{1}^{f, s}$ is obtained by interchanging $A$ and $B$ in the expression for $p_{1}^{h, s}$.

The demands faced by firms 1 and 2 in country $\mathrm{H}$ are, respectively,

$$
\begin{aligned}
q_{1}^{s h} & =\frac{\left(4+2 \gamma-\gamma^{2}\right)(A-B)+4\left(2-\gamma^{2}\right) \theta}{8\left(2-\gamma^{2}\right)} \\
q_{2}^{s h} & =\frac{A(4+3 \gamma)+\gamma(B-2 \theta)}{8}
\end{aligned}
$$

while $q_{1}^{f, s}$ and $q_{2}^{f, s}$ can be obtained by interchanging $A$ and $B$ in the expressions for $q_{1}^{h, s}$ and $q_{2}^{h, s}$ respectively. From these, we retrieve the equilibrium total emissions

$$
\beta q_{1}^{s}=\beta \theta \text { and } q_{2}^{s}=(1 / 2)[(A+B)(1+\gamma)-\theta \gamma] .
$$

reported in (15). Whenever a carbon tax $t_{e}$ on emissions is implemented, the equilibrium prices in the Home and Foreign country are given by

$$
p_{i}^{h}(t)=\frac{A(2+\gamma)+2 t}{4-\gamma^{2}} \quad p_{2}^{f}(t)=\frac{B(2+\gamma+2 t)}{4-\gamma^{2}}
$$

\section{Springer}


for $i=1,2$, where $t=t_{e} \beta$. The corresponding equilibrium quantities are

$$
\begin{aligned}
& q_{1}^{h}(t)=\frac{A(2+\gamma)-t\left(2-\gamma^{2}\right)}{4-\gamma^{2}} \quad q_{1}^{f}(t)=\frac{B(2+\gamma)-t\left(2-\gamma^{2}\right)}{4-\gamma^{2}} \\
& q_{2}^{h}(t)=\frac{A(2+\gamma)+t \gamma}{4-\gamma^{2}} \quad q_{2}^{f}(t)=\frac{B(2+\gamma)+t \gamma}{4-\gamma^{2}}
\end{aligned}
$$

After replacing the carbon tax $t$ with the "equivalent" taxation level, $\bar{t}=(2+\gamma)(A+B-$ $\theta(2+\gamma)) / 2\left(2-\gamma^{2}\right)$, and letting $g^{-1}=(2-\gamma)\left(2-\gamma^{2}\right)$, the corresponding prices are given by the equations

$$
\begin{aligned}
& p_{1}^{h, t}=g\left(A\left(3-\gamma^{2}\right)+B-\theta(2-\gamma)\right) \\
& p_{2}^{h, t}=\frac{g}{2} A\left(4-2 \gamma^{2}+\gamma\right)+\gamma(B+(\gamma-2) \theta)
\end{aligned}
$$

while $p_{1}^{f, t}$ and $p_{2}^{f, t}$ are obtained by interchanging $A$ and $B$ in the expressions for $p_{1}^{h, t}$ and $p_{2}^{h, t}$ respectively, and where the desired tax level, $\tilde{t}$, is the solution to $2\left(2-\gamma^{2}\right) \bar{t}=$ $(2+\gamma)(A+B-\theta(2-\gamma))$. The quantities when $t=\bar{t}$ correspond to Eq. (17).

\section{III: Trade Balance in Values}

Since prices change, the comparison between instruments is tricky when considering trade balances in values. In national accounting, prices are held constant, and hence quantities are compared. However, for the sake of completeness, we also analyze the impact of the two different instruments on the trade balance in values. The trade balance for country $\mathrm{H}$ in values is given by

$$
\begin{aligned}
T B V^{t} & =-\frac{\left(4-\gamma^{2}\right) \theta^{2}+4(1+\gamma)^{2} Z^{2}-8(1+\gamma) \theta Z+2 \gamma^{3} \theta Z}{4\left(2-\gamma^{2}\right)^{2}} \\
T B V^{s} & =-\frac{\left(4-\gamma^{2}\right) \theta^{2}+4(1+\gamma)^{2} Z^{2}-8(1+\gamma) \theta Z}{16\left(1-\gamma^{2}\right)} .
\end{aligned}
$$

The numerator in the trade balance for a standard, $T B V^{s}$, is decreasing in $\theta$ as far as $\theta<\bar{\theta}=2 Z /(2-\gamma)$, therefore one has a sufficient condition for trade balance in value under a standard to be negative by verifying that for $\bar{\theta}$ the numerator is positive, which turns out to be true for all values of $\gamma$. Similarly, for $T B V^{t}$, the same properties apply.

Accordingly, in either case the regulated country experiences a trade deficit in terms of values, resulting in a worsening with respect to the unregulated situation. To understand which of the two policies is less detrimental to the trade balance in values, one can take the difference between the absolute values of $T B V^{t}$ and $T B V^{s}$.

$$
\left|T B^{t}\right|-\left|T B^{s}\right|=\frac{\gamma^{3}\left(\gamma\left(\gamma^{2}-4\right) \theta^{2}-4\left(\gamma^{2}+\gamma\right)^{2} Z^{2}+8(\gamma+1) \theta Z\right)}{-16\left(2-\gamma^{2}\right)^{2}\left(1-\gamma^{2}\right)}
$$

The numerator in (22) is increasing and concave in $\theta$, and therefore in the targeted emission amount $s$, where $s=\beta \theta$. However, for $\gamma=0$ the expression is zero and there is obviously no difference between the effects of the two policies; for $\gamma>0$, the numerator is positive as far as $s$ lies in the interval $(s(\gamma), \bar{s})$, where $s(\gamma)=\beta\left[\frac{\gamma(1+\gamma)}{4-\gamma^{2}} 2 Z\right]$ and $\bar{s} \equiv \beta \bar{\theta}=$ $\beta[2 Z /(2-\gamma)]$, which corresponds to no reduction in emissions, namely $\theta$ equal to the unregulated equilibrium output for the home firm. Hence, for $s(\gamma)<s<\bar{s}$, the desired 


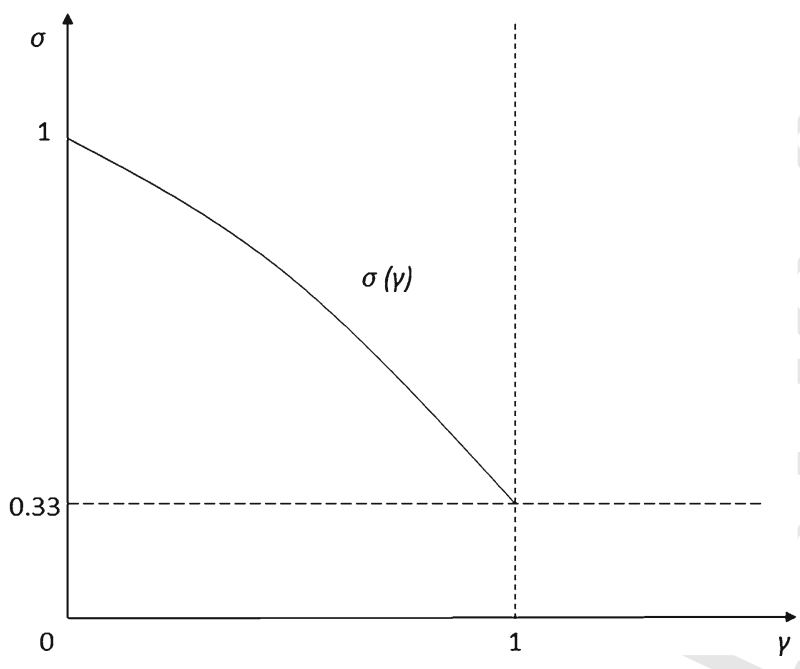

Fig. 2 Percentage reduction

level of emissions, $s$, implies a deficit under a tax exceeding that under a standard-while for $0<s<s(\gamma)$ the reverse relation obtains.

Considering reductions in percentage over the pre-policy emissions level, namely $\sigma \equiv$ $(\bar{s}-s) / \bar{s}$, where $0 \leq \sigma \leq 1$, the tax policy results in worse deficits as far as $\sigma$ is lower than $\sigma(\gamma) \equiv 1-\frac{\gamma(1+\gamma)}{2+\gamma}$ and in better deficits if $\sigma>\sigma(\gamma)$. Since the function $\sigma(\gamma)$ is monotone with $\partial \sigma / \partial \gamma<0$, since $\sigma(0)=1$ and $\sigma(1)=1 / 3$, requiring percentage reductions up to $30 \%$ of pre-policy emissions is sufficient to have a worse trade balance in values under a tax than under an equivalent emission standard. The result can be reversed for high reduction rates and high substitutability parameter; for instance, for a substitutability parameter $\gamma=0.9$, a tax is better than a standard in terms of trade in values only in the required reduction in percentage is above $41 \%$ of the initial emissions. To be precise, the percentage reduction that reverses the result is given as a percentage above the function $\sigma(\gamma)$ in Fig. 2.

Proposition 4 Considering the trade balance in values, a reduction in emissions leads to a trade deficit for the home country; For a given targeted reduction in emissions of the home firm, this deficit in values is worse under a tax than under an emission standard policy, as far as the targeted emissions by the home firm after the policy is above $70 \%$ of the pre-policy level. For lower final emission targets, the trade deficit under a tax can be lower than under a standard policy only if the goods are highly substitutable.

Hence, the different results with either trade volumes, discussed in Sect. 3.3, and trade values are due to the fact that the volume effects dominates under a carbon tax policy.

\section{References}

Amacher GS, Koskela E, Ollikainen M (2004) Environmental quality competition and eco-labeling. J Environ Econ Manag 47(2):284-306

Anderson S, De Palma A, Kreider B (2001) Tax incidence in differentiated product oligopoly. J Public Econ 81:173-192

然 Springer 
Arora S, Gangopadhyay S (1995) Toward a theoretical model of voluntary overcompliance. J Econ Behav Organ 28(3):289-309

Babiker MH (2005) Climate change policy, market structure, and carbon leakage. J Int Econ 65(2):421-445

Barker T, Junankar S, Pollitt H, Summerton P (2007) Carbon leakage from unilateral environmental tax reforms in Europe, 1995-2005. Energy Policy 35(12):6281-6292

Baylis K, Fullerton D, Karney DH (2014) Negative leakage. J Assoc Environ Resour Econ 1(1):51-73

Carlsson F (2000) Environmental taxation and strategic commitment in duopoly models. Environ Resour Econ 15(3):243-256

Feddersen J (Jun. 2012) Why we can't confirm the pollution haven hypothesis: a model of carbon leakage with agglomeration. Economics series working papers 613, University of Oxford, Department of Economics. http://ideas.repec.org/p/oxf/wpaper/613.html

Fischer C (Jul. 2001) Rebating environmental policy revenues: output-based allocations and tradable performance standards. Discussion papers dp-01-22, Resources For the Future. https://ideas.repec.org/p/rff/ dpaper/dp-01-22.html

Fischer C, Fox AK (2012) Comparing policies to combat emissions leakage: border carbon adjustments versus rebates. J Environ Econ Manag 64(2):199-216

Fischer C, Greaker M, Rosendahl KE (Oct. 2012) Emissions leakage and subsidies for pollution abatement. pay the polluter or the supplier of the remedy? Discussion papers 708, Research Department of Statistics Norway. http://ideas.repec.org/p/ssb/dispap/708.html

Fowlie ML (2009) Incomplete environmental regulation, imperfect competition, and emissions leakage. Am Econ J Econ Policy 1(2):72-112

Fowlie M, Reguant M, Ryan SP (Dec. 2012) Market-based emissions regulation and industry dynamics. NBER working paper (18645). https://ideas.repec.org/p/nbr/nberwo/18645.html

Fullerton D, Heutel G (2007) The general equilibrium incidence of environmental taxes. J Public Econ 91(3):571-591

Goulder LH (1995) Effects of carbon taxes in an economy with prior tax distortions: an intertemporal general equilibrium analysis. J Environ Econ Manag 29(3):271-297

Hackner J (2000) A note on price and quantity competition in differentiated oligopolies. J Econ Theory 93(2):233-239

Holland SP, Hughes JE, Knittel CR (2009) Greenhouse gas reductions under low carbon fuel standards? Am Econ J Econ Policy 1(1):106-146

Holland SP (2012) Emissions taxes versus intensity standards: second-best environmental policies with incomplete regulation. J Environ Econ Manag 63(3):375-387

Kuhn HW (1953) In: Kuhn HW, Tucker AW (eds) Extensive games and the problem of information, contributions to the theory of games II. Princeton University Press, Princeton, pp 193-216

Kurtyka O, Mahenc P (2011) The switching effect of environmental taxation within bertrand differentiated duopoly. J Environ Econ Manag 62(2):267-277

Lahiri S, Ono Y (2007) Relative emission standard versus tax under oligopoly: the role of free entry. J Econ 91(2):107-128. https://doi.org/10.1007/s00712-006-0243-1

Mas-Colell A, Whinston MD, Green JR et al (1995) Microeconomic theory. Oxford University Press, New York

Moraga-González JL, Padrón-Fumero N (2002) Environmental policy in a green market. Environ Resour Econ 22(3):419-447. https://doi.org/10.1023/A:1016060928997

Morgenstern RD (2009) Competitiveness and climate policy: avoiding leakage of jobs and emissions. In: Congressional testimony prepared for the committee on energy and commerce-U.S. House of Representatives

Paltsev SV (2001) The kyoto protocol: regional and sectoral contributions to the carbon leakage. Energy J 22(4):53-80

Petrakis E, Xepapadeas A (2003) Location decisions of a polluting firm and the time consistency of environmental policy. Resour Energy Econ 25(2):197-214

Pindyck RS (2007) Uncertainty in environmental economics. Rev Environ Econ Policy 1(1):45-65. https:// doi.org/10.1093/reep/rem002

Requate T (2006) Environmental policy under imperfect competition. In: Tietenberg T, Folmer H (eds) The international yearbook of environmental and resource economics 2006/2007: a survey of current issues. Edward Elgar, Cheltenham

Ryan SP (2012) The costs of environmental regulation in a concentrated industry. Econometrica 80(3):10191061. https://doi.org/10.3982/ECTA6750

Saltari E, Travaglini G (2011) The effects of environmental policies on the abatement investment decisions of a green firm. Resour Energy Econ 33(3):666-685 
Sanna-Randaccio F, Sestini R, Tarola O (2014) Unilateral climate policy and foreign direct investment with firm and country heterogeneity. Nota di Lavoro, Fondazione ENI Enrico Mattei, p 55

Singh N, Vives X (1984) Price and quantity competition in a differentiated duopoly. RAND J Econ 15(4):546554

Toshimitsu T (2008) On the effects of emission standards as a non-tariff barrier to trade in the case of a foreign bertrand duopoly: a note. Resour Energy Econ 30(4):578-584

\section{Springer}

